\title{
A Ambidestria da Prática Docente de Professores de Administração no Ensino Superior
}

\section{The Ambidexterity of the Administration Professors Teaching Practice in Higher Education}

\section{Rafael Fernandes de Mesquita \\ César Ricardo Maia de Vasconcelos}

$\frac{O}{2}$

As escolas de negócio e a formação em Administração têm sido objetos de preocupação devida à crítica à sua desconexão com a realidade empresarial e social e a pouca relevância e/ou aplicabilidade prática de seus produtos. Neste contexto, os professores, que usualmente são classificados em acadêmicos ou de mercado por características de sua formação, experiências de trabalho e prática docente são convidados a desenvolver uma ambidestria que equilibre as duas categorias. Este artigo analisa as possibilidades desta ambidestria ideal entre professores de Administração a partir de uma pesquisa de abordagem metodológica qualitativa com resultados analisados por meio de técnicas lexicográficas apoiadas no uso do software Iramuteq. Os resultados apontam um equilíbrio possível de ser alcançado, desde que cumpridos alguns requisitos, implicando transformações no modelo vigente do ensino superior brasileiro em Administração.

Palavras-chave: Escolas de Negócio. Ensino em Administração. Ensino Superior. Ambidestria.

The business schools and the formation in administration courses have been subjects of concern due to the critics on their disconnection with the business and social reality and the little relevance and/or practical applicability of their products. In this context, teachers, who are usually classified as scholars or practitioners by their previous training characteristics, work experiences and teaching practice are invited to develop an ambidexterity that balances these two categories. This paper analyzes the possibilities of this ideal ambidexterity within management teachers. This is a research with a qualitative methodological approach and results analyzed through lexicographic techniques supported with the use of Iramuteq software. The results point out a balance that can be reached, should provided that certain requirements are fulfilled, implying transformations in the current model of Brazilian business higher education. Keywords: Business Schools. Management Education. Higher Education. Ambidexterity.
Recebido em: 19/12/2018 Aprovado em: 23/04/2019

Rafael Fernandes de Mesquita iD
rafael.fernandes@ifpi.edu.br
Doutor em Administração pela
Universidade Potiguar
PhD in Business Administration -
Universidade Potiguar
Instituto Federal do Piauí
Piripiri/PI - Brasil
César Ricardo Maia de Vasconcelos iD
cesarmvasconcelos@gmail.com
Doutor em Administração pela Université
Pierre Mendes France
PhD in Business Administration -
Université Pierre Mendes France
Universidade Potiguar
Natal/RN - Brasil




\section{Introdução}

As escolas de negócio e a formação superior em Administração têm sido objetos de preocupação de acadêmicos ao longo das últimas décadas (BENNIS; O'TOOLE, 2005; BROWN; RUBIN, 2017). O debate inclui, em grande parte, a formação desconexa dos futuros gestores com a realidade empresarial e social (MINTZBERG, 2004), os resultados de pesquisas que possuem pouca relevância e/ou aplicabilidade (ALPERSTEDT; ANDION, 2017; LAZZARINI, 2017; LI, 2018; PFEFFER; FONG, 2002), a pouca ou nula experiência prática dos professores, que se tornam pesquisadores de formação (KHURANA, 2010) e até uma atribuição de culpa da crise econômica iniciada em 2008 às falhas na formação de gestores (PODOLNY, 2009). Neste contexto, Tushman et al. (2007) e Li (2018) enfatizam que a relevância não acompanha o rigor da ciência administrativa e esta não se insere na prática empresarial, ideia que Vermeulen (2005), Tushman e O'Reilly (2007) corroboram. Chia e Holt (2008) se inserem no debate argumentando em favor da educação de valor para o exercício gerencial, diferindo do modelo que privilegia o rigor acadêmico e quadros conceituais muito abstratos e distantes da realidade.

A indagação de Bennis e O'Toole (2005, p. 96') em "como as escolas de negócio perderam seu caminho?" é respondida a partir da descrição do padrão de excelência acadêmica adotado, considerado pelos autores como inapropriado. Os índices que avaliam o desempenho são calculados quase que exclusivamente a partir da produção científica, com escassa ênfase nas práticas empresariais. A analogia à situação brasileira poderia ser percebida se a comparação fosse direcionada à pós-graduação stricto sensu, cujo sistema de avaliação frequentemente recebe críticas pelos pesos atribuídos à produção científica de seu corpo docente e discente (MESQUITA et al., 2014; VIZEU; MACADAR; GRAEML, 2016; VOSGERAU; ORLANDO; MEYER, 2016), críticas também presentes em contextos internacionais (SALTER; SALANDRA; WALKER, 2017). Soma-se a isso a crise institucional e de

1 As citações diretas de trechos de publicações escritas originalmente em língua inglesa foram traduzidas livremente pelos autores e o resultado é identificado entre aspas. Nesta, há uma tradução livre de: "How Business Schools Lost Their Way?" (BENNIS; O'TOOLE, 2005, p. 96). Os trechos em língua inglesa nas demais citações diretas não estão identificados, mas as fontes de referência permanecem. 
legitimidade que o país enfrenta, o que envolve tanto organizações privadas quanto públicas e à ciência da Administração urge implicar sentido e impacto social (ALPERSTEDT; ANDION, 2017).

O mérito da investigação científica em Administração e, consequentemente, dos centros de pesquisa que sediam estes estudos e formam novos profissionais é posto em xeque quando o préstimo e a pertinência não são percebidos (MILES, 2017). A crítica é amparada em uma possível dicotomia inerente ao campo e na historicidade de valorização da orientação à pesquisa, em detrimento da práxis técnica na profissionalização de novos graduados.

A divisão de professores que se encaixam particularmente em um destes dois grupos é popularmente conhecida. Apesar da categorização não ser exclusiva (CARTON; UNGUREANU, 2017), acadêmicos e práticos são conhecidos por suas características marcantes, como a busca ou utilização de conhecimento de base científica ou de experiências prévias e de cunho prático, respectivamente. Uma ambidestria desejável que equilibrasse características de ambos os tipos na atuação de docentes em cursos de gestão, de acordo com Markides $(2007,2011)$, auxiliaria na solução da problemática do processo de formação de profissionais, o que pode ser traduzido em fases independentes de dedicação ao desenvolvimento de cada uma das "mãos" (HIGSON; KASSEM, 2016). Isto posto, apresenta-se o seguinte problema: como docentes, que também são egressos de cursos de Administração, compreendem esta possibilidade da ambidestria associada à prática de mercado e à pesquisa acadêmica?

Diante das considerações, o objetivo deste artigo é analisar as possibilidades de uma ambidestria ideal que envolva a prática de mercado e a pesquisa acadêmica para professores de Administração. A lacuna teórica e a problematização empírica se inserem em um contexto contemporâneo de óbices à identificação/alcance da relevância prática e harmonia com as bases teóricas para a ciência e para os professores da administração. O problema é recentemente apresentado, como informam Alperstedt e Andion (2017) Lazzarini (2017) e Pfeffer e Fong (2002). O presente estudo tornou-se possível a partir de uma metodologia de abordagem qualitativa com dados coletados por meio de formulários online, distribuídos e acessados por docentes de todas as regiões brasileiras, com análises apoiadas no uso do software de análise lexicográfica Iramuteq. 
As seções seguintes deste artigo apresentam uma contextualização da formação em cursos da área de gestão, os procedimentos metodológicos, resultados do estudo, discussão e conclusão.

\title{
Formação em Administração
}

\begin{abstract}
Antes da existência de escolas de negócios, havia empresários e gestores de negócios. Antes da existência de escolas de farmácia, a distribuição de medicamentos para fins médicos era praticada. Antes da existência de escolas de jornalismo, havia jornalistas. (De fato, alguns podem argumentar que a era de ouro do jornalismo ocorreu antes do advento das escolas de jornalismo.) Esses exemplos têm como objetivo mostrar que os profissionais - que hoje recebem treinamento formal em escolas profissionais em universidades - uma vez praticaram sua profissão sem o benefício desse treinamento formal. Como eles adquiriram esse treinamento? Era um treinamento baseado na prática, seguindo essencialmente o mesmo modelo das guildas de artesanato (ou seja, aprendiz). [...] Alguns antecedentes sobre o que motivou a transição da prática para a formação universitária, o que foi perdido por essa mudança e o que foi ganho têm relação com o atual relacionamento entre a universidade e suas escolas profissionais (MILES, 2016, p. 115).
\end{abstract}

As escolas de Administração surgiram antes mesmo de sua constituição como ciência, que se deu com os trabalhos de Taylor na transição do século XIX para o século XX (KHURANA, 2010). Desde então, este campo, como ciência, tem sido contestado (ALPERSTEDT; ANDION, 2017). A profissionalização, a partir da inserção de ensino de molde universitário na formação do administrador, se configurava, à época, na busca por legitimação e postos de trabalho de alto nível, essencialmente na afirmação de que havia fundamentos científicos e cognitivos para uma gestão eficaz (KHURANA, 2010) e que estes poderiam ser ensinados em sistemas escolares (ALCADIPANI; BERTERO, 2014). A possibilidade formal de sistematização, transmissão e apreensão do que é gestão nos moldes de educação tradicional legitimou seu reconhecimento como atividade relevante (BARROS et al., 2011).

O ensino de Administração no Brasil, resultante da crescente influência da cultura norte-americana no período pós-segunda guerra mundial (BERTERO, 2006), tem sua gênese nos estados brasileiros de São Paulo-SP e Rio de Janeiro-RJ, respectivamente com a Escola Superior de Administração de Negócios (Esan/SP) e 
a Escola de Administração de Empresas de São Paulo da Fundação Getúlio Vargas (Eaesp/SP). No que tange à administração pública, teve início com a Escola Brasileira de Administração Pública (Ebap/RJ), posteriormente denominada Escola Brasileira de Administração Pública e de Empresas (Ebape/RJ) (MESQUITA et al., 2014). Estas escolas, posteriormente influenciariam a constituição de outros cursos de Administração no Brasil e na América Latina, perpetuando a influência estadunidense (ALCADIPANI; BERTERO, 2014).

O modelo brasileiro apresentava-se em dois eixos nos seus primeiros cursos, um proveniente das ciências sociais, e outro da administração como uma profissão modernizadora, com o propósito de formar administradores técnico-profissionais. Este último eixo era uma consequência do desenvolvimento econômico e empresarial, com a crescente necessidade de gestores para atender à demanda derivada da maior competitividade (MESQUITA et al., 2014). As universidades, além de legitimar a profissão, considerando o prestígio da ciência per se, ampliaram o suporte à progressiva profissão a partir da percepção de empresários sobre as contribuições dos profissionais graduados (KHURANA, 2010).

A pós-graduação brasileira stricto sensu em administração tem seu início nos princípios da década de 1970, com programas de mestrados e, ainda na mesma década, com programas de doutorado apenas em São Paulo. Em 2012, respondia pela quinta posição em matrículas da pós-graduação no Brasil, num universo de 47 áreas do conhecimento (CIRANI; SILVA; CAMPANARIO, 2012). O desenvolvimento desses programas se deu em um contexto contemporâneo à reforma universitária brasileira de 1968. Essa reforma da universidade brasileira foi paradoxal, pois possibilitou o desenvolvimento das instituições de ensino superior (IES) públicas e criou um ambiente propício à articulação do ensino e pesquisa (MESQUITA et al., 2014). Contudo, também impulsionou o surgimento do ensino superior privado de caráter empresarial, de propósito profissionalizante e distanciado da atividade de investigação científica.

As IES públicas não conseguiam atender às demandas crescentes por vagas na educação superior e este cenário foi um dos impulsos à proliferação de IES privadas. Destas, poucas se dedicaram à pesquisa e avançaram em participação de mercado (MESQUITA et al., 2014). O modelo de ensino público se aproximava do neo-humboldtiano, cuja principal característica era a associação obrigatória entre 
ensino e pesquisa, enquanto o privado se aproximava de um modelo neo-napoleônico, com vistas à formação mais profissional e maior dedicação às atividades de ensino (MARTINS, 2009). Apesar de as escolas de negócio continuarem avaliando seu desempenho por rankings acadêmicos de produção e difusão do conhecimento, este formato tem recebido diversas críticas por priorizar a faceta científica da administração e reduzir o esforço na promoção de integração entre teoria e prática e ensino sobre valores e ética (MURILLO; VALLENTIN, 2016; PODOLNY, 2009). Este é o modelo adotado nas avaliações da CAPES (Coordenação de Aperfeiçoamento de Pessoal de Nível Superior), fundação vinculada ao Ministério da Educação do Brasil - MEC, comum para todas as áreas do conhecimento. Esta lógica privilegia o quantitativo das publicações em periódicos, avaliando também o ranqueamento destas revistas acadêmicas, em uma lógica de produtividade e competitividade. Além disso, Mintzberg (2004) acrescenta que diversos professores sentiam um desconforto ao perceber que o conteúdo de suas aulas possuía pouca conexão com a realidade empresarial e social, o que o levou a iniciar um projeto de curso que solucionasse este problema.

A transformação da configuração tradicional do ensino em outra que também enfatize atividades de campo direcionadas ao desenvolvimento de habilidades práticas, gradualmente implica ganhos de inovação e gestão tecnológica, essenciais para contextos de economia em desenvolvimento (GONZALEZ-BRAMBILA; JENKINS; LLORET, 2015). Entretanto, a mudança não precisa ser radical e a expertise que caracteriza as escolas de negócio atualmente, o rigor na forma de pensar problemas e o background teórico já habitual, oferecem vantagens nesta adaptação, pois, assim como afirmam Pfeffer e Fong (2002, p. 93) "não há razão para que, em um mundo que procura por conhecimento e capacitação, as escolas de negócio não prosperem em ambos". Lazzarini (2017) acrescenta ao debate o preconceito com determinados temas de cunho empresarial, mas que permanecem atuais no campo da ciência, como a "produtividade" que, à primeira vista é diretamente associada aos estudos de tempos e movimentos de Frederick Taylor, mas que continua discutida à exaustão quando se trata dos motivos do baixo crescimento da economia no Brasil.

Chia e Holt (2008) alinham-se ao debate argumentando em favor da educação de valor para o exercício gerencial, diferindo do modelo que privilegia o rigor acadêmico e quadros conceituais muito abstratos e distantes da realidade. Neste 
sentido, os autores usam o exemplo da medicina e da advocacia que, pelo grande valor social percebido e ausência de impedimentos (segredos empresariais) na divulgação do alcance de novos conhecimentos, têm alcance maximizado e interesse populacional. Bennis e O'Toole (2005) esclarecem que esses anseios por mudanças são desencadeados por críticas de estudantes, trabalhadores, empregadores e gestores de IES. Os autores descrevem como a cultura das escolas de negócio, que adotam um padrão de excelência acadêmica para avaliação de desempenho, se torna inapropriada ao campo. Somada a este padrão, a tradição de isolamento das grandes escolas, faz que os "muros altos" sejam intransponíveis para o estabelecimento de relações com parceiros internacionais de países em desenvolvimento, o que poderia endereçar problemas de pertinência real e localizada (CURRIE; DAVIES; FERLIE, 2016).

Diferente de grande parte das hard sciences que avançam quase que exclusivamente em laboratórios, a área da gestão, Bennis e O'Toole (2005) afirmam, é profissional e suas escolas também o deveriam ser. Quanto mais próximo da sociedade e do ambiente de negócios, mais as business schools conseguirão se manter competitivas (WILSON; THOMAS, 2012). A crítica, apesar de direcionada à ciência da Administração, não pretende retirar sua legitimidade, mas complementá-la, corroborando uma pluralidade que envolva ambos os eixos, acadêmico e profissional, tanto na IES a nível institucional, quanto para o docente, que atua diretamente na formação de novos profissionais.

De acordo com os achados de Souza-Silva e Davel (2005, p. 121), há quatro categorias de professores de administração no Brasil, "(a) alta experiência docente e alta vivência gerencial; (b) alta experiência docente e carência de vivência gerencial; (c) baixa experiência docente e alta vivência gerencial; e (d) baixa experiência docente e baixa vivência empresarial". Conforme os autores, o tipo ideal seria aquele que apresenta em alto nível, ambas a experiência docente e a vivência gerencial. Aquele professor que não consegue transitar bem em um (ou em ambos) dos campos, seja ele no campo da docência ou da vivência gerencial, ainda, segundo os autores, é penalizado: em reclamações por parte dos alunos que se sentem prejudicados se um campo não é contemplado; em dificuldades de ascensão de carreira e obtenção de empregos; ou mesmo com sua demissão. A dificuldade é acentuada, pois o professor tende a mimetizar práticas de seus pro- 
fessores, quando discente, e, assim, levar à frente as mesmas características que foram balizadoras de sua formação.

Apesar da categorização docente não ser exclusiva e ser percebida por características de sua formação, experiências de trabalho e prática atual (CARTON; UNGUREANU, 2017), acadêmicos e práticos são conhecidos por seus aspectos peculiares, como a busca ou utilização de conhecimento de base científica ou de experiências prévias e de cunho prático, respectivamente. Aqui, como uma forma de exemplificar algumas implicações desta disputa, Cho et al. (2017) destacam que as empresas com diretores, que também são acadêmicos, exibem melhor desempenho de responsabilidade social corporativa. Aqueles que detêm ambas "têm um pé em cada um dos mundos da academia e da prática e são claramente interessados em avançar ambas as causas da teoria e da prática" (TENKASI; HAY, 2008, p. 50). Carton e Ungureanu (2017) analisaram os múltiplos papéis dos profissionais que acumulavam ambas as características de acadêmicos e profissionais (scholars-practitioners), compreendendo como resposta três principais papéis: o professor - atividades de sala de aula dentro e fora das IES; o pesquisador - condução e planejamento de pesquisas, participação em eventos e produção científica; e o prático - atividades desenvolvidas com stakeholders fora do ambiente acadêmico. Uma ambidestria desejável, de acordo com Markides (2007, 2011), auxiliaria na solução da problemática do processo de formação de profissionais da gestão.

\section{Procedimentos Metodológicos}

A pesquisa se caracteriza como de natureza descritiva e de abordagem qualitativa (MESQUITA; MATOS, 2014). Para a etapa de produção de dados, um formulário online (Google docs) estruturado com questões abertas ficou ativo durante os meses de setembro e outubro de 2017 e foi compartilhado em redes sociais e grupos de professores de Administração em aplicativos de mensagem instantânea. $O$ formulário foi respondido por professores residentes nas cinco regiões brasileiras, atingindo um número total de 54 participantes, sendo $68,4 \%$ da região nordeste, $20,4 \%$ da região norte, 5,6\% da região sul, 3,8\% da região centro-oeste e 1,9\% da região sudeste. 
Para a elaboração do instrumento de pesquisa e o estabelecimento de critérios para indicar o término da coleta de dados, foram seguidas as seguintes recomendações de Minayo (2017): atenção às homogeneidades e diferenciações internas do grupo a ser investigado; a limitação de sujeitos aos atributos que os pesquisadores pretendiam conhecer; consideração de um número suficiente de participantes que propicie reincidências nas respostas; complementaridade de informações obtidas; e mapeamento abrangente do quadro empírico. Além disso, também foram consideradas a exaustividade na contemplação de todos os aspectos do estudo, a representatividade das características essenciais do universo pretendido, a homogeneidade em relação aos atributos dos interlocutores e a pertinência no conteúdo das respostas aos objetivos do estudo.

Com a finalidade de atender ao objetivo de analisar as possibilidades de uma ambidestria ideal que envolva a pesquisa acadêmica e a experiência de prática de mercado para professores de Administração, as perguntas do formulário estavam subdivididas em dois eixos principais: a experiência discente e a atuação docente. As perguntas eram curtas e abertas e, para o primeiro eixo, os participantes foram convidados a relatar suas experiências enquanto discente de graduação, discorrendo sobre a prática de seus professores e se estes possuíam características mais acadêmicas ou de mercado, esclarecendo qual destes dois era o seu grupo favorito. Para o segundo eixo, relataram sua identificação atual como pesquisador/ acadêmico ou mercado/profissional, se consideram possível um equilíbrio entre as duas possibilidades na sua prática e na atuação de outros professores.

Os dados obtidos foram preparados e exportados para análise lexicográfica com apoio do software Iramuteq (Interface de R pour Analyses Multidimensionnelles de Textes et de Questionneires). A partir de análises estatísticas multivariadas, o software categoriza dados textuais, reduzindo as palavras com base em seus radicais (lematização) identificando formas ativas, suplementares e organizadas por frequência (CAMARGO; JUSTO, 2013), permitindo "a compreensão do ambiente de sentido das palavras e, portanto, indica[ndo] elementos das representações referentes ao objeto estudado" (COSTA et al., 2016, p. 3).

Para este trabalho foram utilizados dois métodos analíticos, a Análise de Similitude (AS) e a Classificação Hierárquica Descendente (CHD). A AS identifica as coocorrências entre palavras, indicando a conexidade entre elas, possibilitando a 
identificação da estrutura do corpus textual. A análise de coocorrências "dedica-se a assinalar as presenças simultâneas (coocorrência ou relação de associação) de dois ou mais elementos na mesma unidade de contexto" (BARDIN, 2011, p. 259-260), revelando sentidos de associação entre termos. A CHD organiza os segmentos de texto em classes em função de seus vocabulários já lematizados. Estas classes apresentam unidades de contexto elementar (UCE) semelhante entre si e diferente das demais. As UCE são as unidades de contexto iniciais, segmentos de texto, já lematizadas. Além disso, a CHD permite que se recuperem, no corpus original, os segmentos de texto que estão associados a cada classe, o que permite uma interpretação mais acurada de sentido do que cada classe representa e ao quê está associada. Estes segmentos são apresentados na seção de resultados acompanhados da letra "P" e uma numeração correspondente à ordem de recebimento do formulário preenchido, assegurando o anonimato dos participantes.

Os textos resultados das entrevistas foram divididos em dois corpora, um corpus para cada eixo. O primeiro eixo, da experiência discente, foi analisado a partir da técnica de AS e o segundo eixo, da atuação docente, com a técnica de AS e CHD, possível devido ao maior volume de informações. Conforme recomendações de uso do software Iramuteq, para a utilização de texto proveniente de entrevistas, há sugestão de uso de um número superior a 20 registros. Em entrevistas nas quais há mais de um tema, cada tema deve ser analisado em separado, em corpus próprio. Para inclusão dos elementos nas classes da CHD, foram respeitadas à retenção de segmentos de texto superior a $70 \%$ e qui-quadrado $\left(X^{2}\right)$ de associação da palavra à classe com significância estatística em 95\% (CAMARGO; JUSTO, 2013).

Os resultados, discussões e conclusões são apresentados nas seções seguintes.

\section{Resultados}

A pesquisa possui respondentes representantes de todas as regiões brasileiras. Em relação ao tempo de trabalho como docente em cursos de Administração, os professores responderam: entre 1 e 3 anos (14,8\%), entre 3 e 5 anos $(27,8 \%)$, entre 5 e 10 anos (18,5\%), há mais de 10 anos (38,9\%). O vínculo empregatício 
está dividido em público $(59,3 \%)$, privado $(33,3 \%)$ e ambos $(7,4 \%)$. O período passado desde a conclusão do curso de graduação está dividido em: entre 3 e 5 anos $(7,4 \%)$, entre 5 e 10 anos (37\%) e há mais de 10 anos (55,6\%).

A Figura 1 apresenta os resultados da AS para o corpus originado a partir das respostas direcionadas ao eixo de experiência discente. As três palavras principais sintetizam o conteúdo do corpus, pois os professores respondentes relataram, em diversos casos, que os seus docentes não possuem experiência de mercado ou esta não era evidente e/ou utilizada nas aulas. As palavras associadas ao termo "mercado" denotam a valorização desta característica, tais como "gosto", "gostar", "mais" e "preferir". Os fragmentos a seguir justificam esta interpretação.

\footnotetext{
Os meus professores não conheciam muito das práticas de administração, embora conhecessem muito sobre os pressupostos teóricos (P22).

Prática limitada e curso puramente teórico $(\mathrm{P} 1)$.

Poucos professores trouxeram o elo entre prática e teoria. Muitos falavam apenas a parte teórica sem aplicabilidade (P8).

Muitos professores com boa didática e conhecimento teórico. Tivemos pouca prática (P45).

Eles ministraram muita teoria sem levar a experiência de mercado para a sala de aula (P39).
}

As demais palavras associadas ao termo "professor" indicam como foram os relatos dos participantes, descrevendo o bom relacionamento com seus formadores e como esta relação despertou o interesse para a intenção de carreira na docência.

Os resultados da AS sobre o corpus do eixo "Prática Docente", Figura 2, apresenta o "sim" como termo principal. Os fragmentos associados indicam a possibilidade, as justificativas, os meios e os modos de como um equilíbrio ambidestro de características acadêmicas e práticas de mercado podem ocorrer. Os outros termos em destaque estão associados e amparam esta interpretação, conectando "pesquisa" e "pesquisador" a "mercado" com diversas palavras de associação no caminho das conexões, tais como "também", "experiência”, "organização", "precisar" e "acadêmico".

Em complemento à análise do corpus "Prática Docente", para a realização da CHD foram analisados 185 segmentos de texto, 3057 ocorrências distribuídas em 936 formas e 702 lemas, com uma retenção de 78,92\% do total para constituição das classes apresentadas na Figura 3. 
Figura 1 Análise de Similitude sobre o corpus "Experiência Discente".

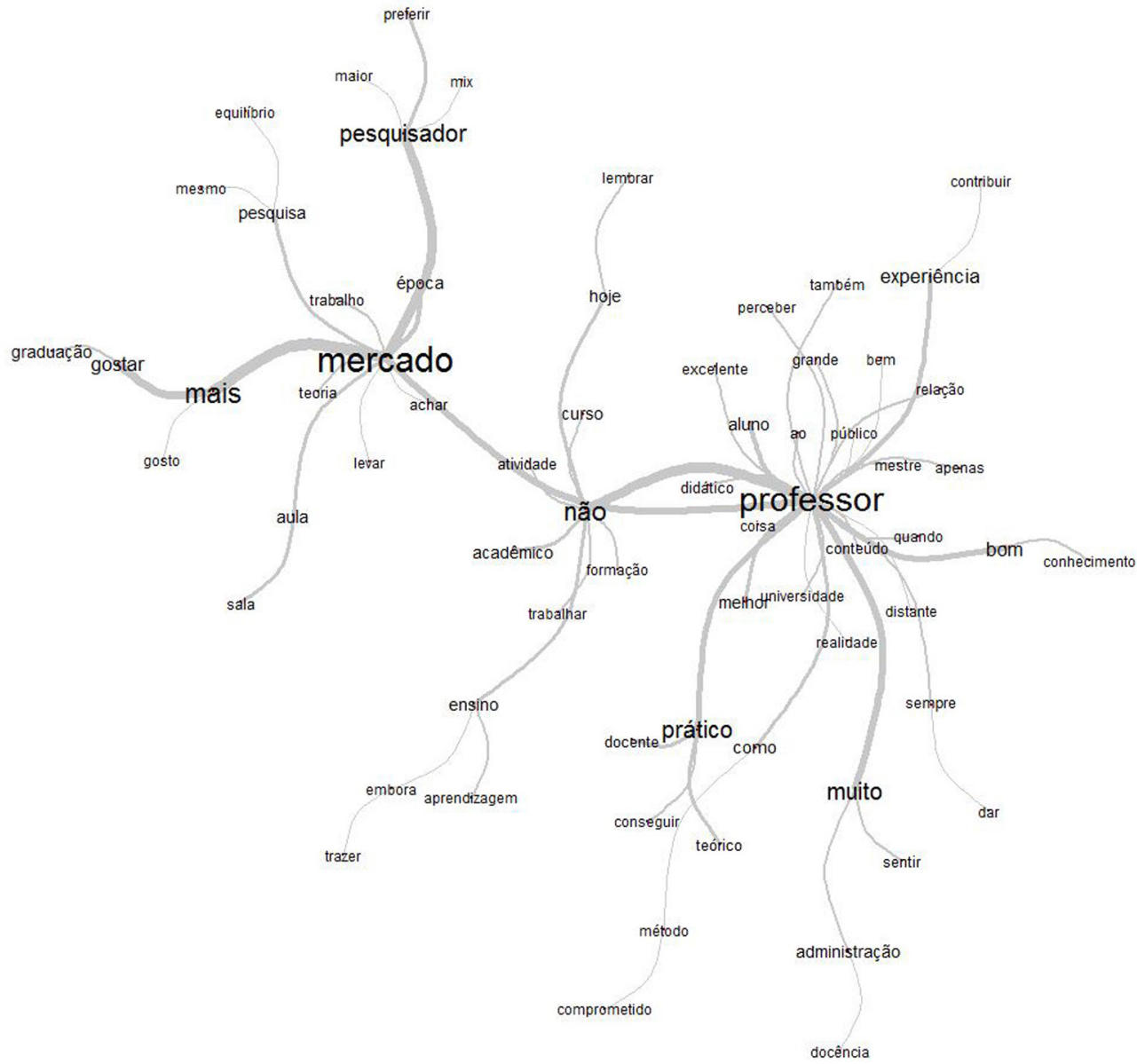

Fonte: Elaboração própria a partir de outputs do software Iramuteq. 
Figura 2 Análise de Similitude sobre o corpus "Prática Docente".

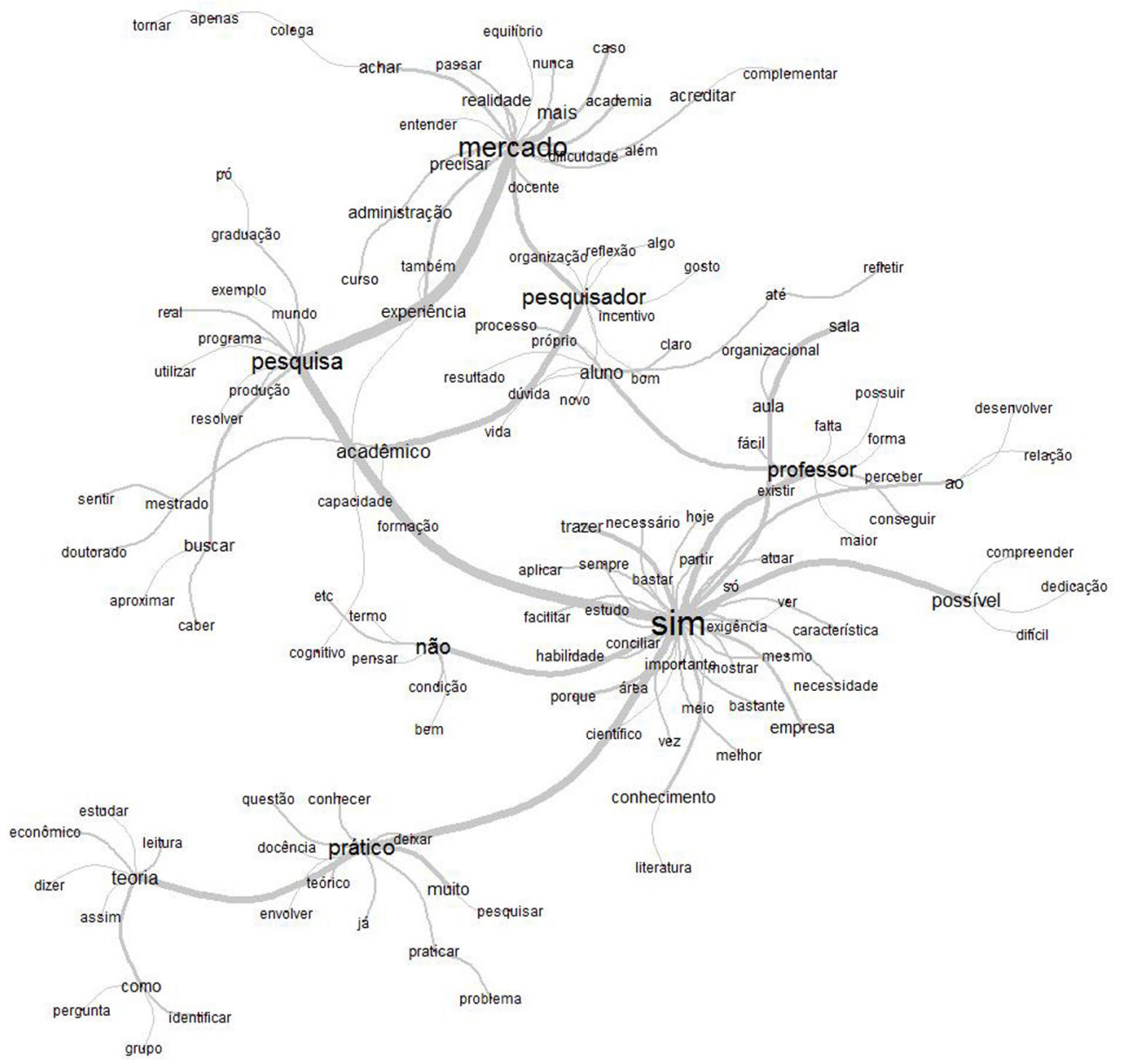

Fonte: Elaboração própria a partir de outputs do software Iramuteq. 
Figura 3 Dendrograma de Classificação Hierárquica Descendente do corpus "Prática Docente".

\begin{tabular}{|c|c|c|c|c|c|}
\hline \multicolumn{6}{|c|}{$\begin{array}{c}\text { Dendrograma de Classificação Hierárquica Descendente } \\
\text { Retenção de Segmentos de Texto } 78,92 \%\end{array}$} \\
\hline $\begin{array}{c}\text { Classe 6: } \\
\text { Identificação } \\
\text { Acadêmica } \\
15 \% \\
22 \text { UCE }\end{array}$ & $\begin{array}{c}\text { Classe 2: } \\
\text { Identificação } \\
\text { de Mercado } \\
19,1 \% \\
28 \text { UCE }\end{array}$ & $\begin{array}{c}\text { Classe 4: } \\
\text { Viabilidade } \\
\text { Ambidestra } \\
\text { Mercado } \\
17,1 \% \\
23 \text { UCE }\end{array}$ & $\begin{array}{c}\text { Classe 3: } \\
\text { Equilíbrio } \\
15,7 \% \\
27 \text { UCE }\end{array}$ & $\begin{array}{c}\text { Classe 5: } \\
\text { Viabilidade } \\
\text { Ambidestra } \\
\text { Pesquisa } \\
15,7 \% \\
23 \text { UCE }\end{array}$ & $\begin{array}{c}\text { Classe 1: } \\
\text { Experiências } \\
17,1 \% \\
25 \text { UCE }\end{array}$ \\
\hline Palavra & Palavra & Palavra & Palavra & Palavra & Palavra \\
\hline Pesquisador & Mercado** & Possível $^{* *}$ & $\operatorname{Sim}^{* *}$ & Aluno** & Realidade $^{* *}$ \\
\hline Acadêmico & Precisar & Vez $z^{* *}$ & Trazer & Muito" & Nunca** \\
\hline \multirow[t]{23}{*}{ Gosto* } & Academia"* $^{*}$ & Aplicar** & & Melhor ${ }^{* *}$ & Identificar" \\
\hline & Administração* & $\operatorname{Sim}^{* *}$ & & Necessário* & Graduação"* \\
\hline & Acreditar & Teoria** & & Importante & Condição* \\
\hline & Maior & Não*" & & Processo" & Além** \\
\hline & Mais* & Sempre* & & Próprio** & Experiência ${ }^{* *}$ \\
\hline & & Exigência** & & Conhecimento* & Até $^{* *}$ \\
\hline & & Prático** & & Caber & Aluno* \\
\hline & & Empresa* $^{* *}$ & & Mesmo* & Não** \\
\hline & & Como* & & Vida* & Conhecer* \\
\hline & & Reflexão* & & Envolver & Programa* \\
\hline & & Dizer & & Claro* & Como* \\
\hline & & Compreender & & Buscar & Pesquisa* \\
\hline & & & & & Termo* \\
\hline & & & & & Refletir \\
\hline & & & & & Estudar \\
\hline & & & & & Docência* \\
\hline & & & & & Capacidade \\
\hline & & & & & Existir \\
\hline & & & & & Econômico* \\
\hline & & & & & Bem \\
\hline & & & & & Bastar ${ }^{*}$ \\
\hline & & & & & Caso* \\
\hline & & & & & Professor ${ }^{*}$ \\
\hline
\end{tabular}

Legenda: $X^{2}$ " $p<0,01 /$ " $p<0,05$.

Fonte: Elaboração própria a partir de outputs do software Iramuteq. 
A classe 6 é a mais representativa do corpus, pois determina as demais e está relacionada diretamente à classe 1. Nomeada "Identificação Acadêmica", a partir de seu vocabulário típico, corresponde a $15 \%$ dos segmentos de texto analisados do corpus original. As palavras selecionadas, quando comparadas aos fragmentos correspondentes à classe, indicam a identificação do professor às características acadêmicas de sua atuação docente, associando-a ao trabalho de pesquisador. Os fragmentos a seguir exemplificam a classe.

Pesquisador acadêmico, sem dúvida. Emendei mestrado e doutorado e nesse meio tempo só o que fiz foi pesquisar e dar aula. Se quisesse me inserir em alguma empresa hoje, acredito que teria dificuldade pela distância temporal que meus empregos anteriores estão da atualidade. Sinto-me defasada em parâmetros técnicos (P19).

Pesquisador, por ter dedicação exclusiva à docência (P24).

Os recortes de fala anteriores apresentam elementos que se repetem nas entrevistas: o distanciamento das empresas e a dedicação exclusiva à docência, este último como um fator responsável pelo primeiro. A exclusividade docente é vista como algo que dificulta o contato com as organizações, para além das instituições de ensino de vínculo do participante, e que o aproxima do campo da pesquisa. Esta situação gera uma problemática de compatibilidade, pois o regime de dedicação exclusiva em instituições públicas de ensino, como estaduais e federais, envolve extensa carga horária semanal (40 horas/aula) dividida entre atividades em sala de aula, de planejamento e atividades administrativas, quando aplicável. Além disso, outras ocupações podem ser somadas ao rol de atribuições acadêmicas, como a participação em bancas, eventos e orientações. Tarefas que, salvas as exceções, não se aproximam da prática de mercado.

A classe 1 "Experiências" destaca relatos que descrevem o porquê da identificação do professor com uma prática mais conectada ao mercado ou à pesquisa. As narrações indicam a relação entre discente e docente, recursos didáticos como metodologias ativas e uso de casos de ensino e as dificuldades enfrentadas por ambos os tipos categóricos, tal como evidenciado nas falas seguintes.

Existem casos de professores que passam por todos os níveis de graduação sem ter uma experiência de mercado sólida e cabe a esse profissional reconhecer que falta vivência para enriquecer sua aula e suas pesquisas. Buscar se aproximar um pouco mais 
da realidade organizacional. Assim como também existem professores com muita experiência e bagagem prática, mas deixam a desejar na capacidade de comunicação escrita. Orientam pesquisas sem conhecer a teoria no nível de profundidade requerido (P37). Sinto uma carência da orientação à pesquisa, principalmente em IES que não possuem programas de pós-graduação stricto sensu e possuem poucos professores com mestrado e doutorado no seu corpo docente (P52).

A classe 2, determinada pela classe 1, nomeada de "Identificação de Mercado", é formada pela congruência das respostas dos participantes que se identificaram mais com o ambiente de negócios. Os recortes das entrevistas: "É mais dinâmico e facilita a entrada no mercado de trabalho mais rapidamente" (P21), "É interessante o professor compartilhar suas experiências do mercado para que a aula tenha maior credibilidade" (P31) e "Vejo alguns PPGA com maior aproximação do mercado. Acredito e defendo essa aproximação de academia e mercado" (P34) ilustram a classe e apresentam a justificativa de identificação dos respondentes.

Apesar de ser uma classe que apresenta o mercado como recognição, a associação com a prática acadêmica ainda é evidente, como em: "Acho mais fácil um professor de perfil acadêmico conseguir trazer o mercado para a sala de aula que um professor muito atuante no mercado fazer pesquisa" (P53) e "Acho que sim, mas não é um trabalho fácil. Tem professores que estão há anos na pesquisa e não conseguem associar com o mercado de trabalho e vice-versa" (P15). Os professores percebem esta problemática e sua influência na sua prática docente, bem como na prática dos demais colegas de profissão. A dissociação torna-se evidente, quando o foco de percepção é "o outro", seja ela no eixo da pesquisa acadêmica, seja ela na prática de mercado.

As classes 5 e 4, nomeadas de "Viabilidade Ambidestra", apresentam como a ambidestria é possível, justificando como inserir contribuições acadêmicas na prática de mercado (classe 5) e experiências de mercado no ensino (classe 4). Alguns fragmentos que justificam a classe 5: "O mercado revela as necessidades de produção de conhecimento e a pesquisa faz o profissional ser melhor fundamentado em termos técnicos e práticos" (P7), "O aluno precisa de proatividade na busca pelo próprio conhecimento, algo que o professor pesquisador está mais preparado para fazer" (P20) e "O professor da pesquisa tem que buscar atender à comunidade com estudos que levem às soluções do mercado" (P19). Os segmentos de texto que o 
software selecionou para a classe 4 são: "as características de mercado devem ser aproximadas com as IES para associar prática e teoria" (P49), "Métodos de ensino como ABP e metodologias ativas podem agregar nesse equilíbrio" (P37) e "Professores podem desenvolver projetos e parcerias com empresas" (P2). Ambas as classes apresentam elementos que auxiliam na compreensão da possibilidade de uma ambidestria a partir da inserção de atividades ou aspectos de experiências próprias da profissão que facilitariam este processo, conforme os relatos.

A classe 3 "Equilíbrio" expõe a consideração da possibilidade de balanceamento entre as características de mercado e de pesquisa na prática docente, como em "Conexão e atualização condizentes com a necessidade" (P29), "É necessário trazer exemplos práticos para facilitar o aprendizado" (P39), "Um complementa o outro" (P43), "Sim, até porque deve haver esse equilíbrio" (P14) e "Na nossa área, ambas as perspectivas são essenciais" (P44). A classe 3 se diferencia das anteriores por apresentar algo já consolidado nos relatos com real e possível. Enquanto as classes 4 e 5 implicam em mudanças, a classe 3 oferece uma situação em que a ambidestria é viável e pode ocorrer.

\section{Discussão}

O problema que Bennis e O'Toole (2005) apresentam se repete nos resultados deste estudo. O modelo de excelência acadêmica privilegia uma carreira direcionada para títulos de pós-graduação, como mestrado e doutorados acadêmicos, com vistas às melhorias salariais e dedicação exclusiva à universidade. $A$ generalização de adoção de plano de carreira derivada deste padrão, que é implementado nas instituições públicas de ensino superior, implica uma dificuldade na aproximação com o mercado, conforme relatado pelos professores. "O problema não é as escolas de negócio adotarem o rigor científico [derivado da formação em nível stricto sensu], mas elas abandonarem outras formas de conhecimento" (BENNIS; O'TOOLE, 2005, p. 104). Como o formato adotado pelas IES brasileiras para os currículos e os cursos de Administração é similar e influenciado pelas mesmas fontes (ALCADIPANI; BERTERO, 2014), a prática se torna limitada e condicionada a esta configuração. 
Os "praticantes", uma categoria negligenciada a partir da legitimação da atividade pelo título que corresponde à formação, leva à crença de que "por não se enquadrarem nos parâmetros necessários para serem considerados verdadeiros, são carentes de racionalidade e razoabilidade" (BARROS et al., 2011, p. 46). Desta forma, o saber que é transmitido pelas lógicas externas à formal é reduzido e a academia, que se apropria de saberes práticos em sua gênese, se afasta destes à medida que sistematiza sua transmissão (BARROS et al., 2011). O saber administrativo no Brasil, de acordo com Curado (2001), se consolida em três fases distintas: o período do saber prático, até 1955, que se relacionava a um saber não sistematizado com as ações dos gestores baseadas na experiência; o saber tecnológico, da década de 1950 até a década de 1990, caracterizado pela sistematização deste saber por meio da adoção e disseminação de diversos modelos de gestão; e o saber plural, a partir da década de 1990, com o questionamento da univocidade do saber administrativo, substituindo-o pela busca de um modelo específico adaptado à realidade de cada empresa. O período de declínio do saber prático coincide com o surgimento das escolas de administração no Brasil (BARROS et al., 2011).

Alperstedt e Andion (2017, p. 630) enfatizam: "as práticas contém em si essa magia de mudar realidades" e no Brasil, a lógica do publish or perish, derivada de práticas anglo-saxãs adotadas na avaliação de cursos e escolas, reflete na produção acadêmica tornando-a uma fábrica que visa à produtividade com consequente distanciamento da realidade social. A práxis docente está inserida neste contexto e recebe influência desta lógica de produtividade.

Os resultados não se afastam da literatura internacional e, mesmo que as escolas brasileiras de negócios tenham adquirido identidade própria a partir de um híbrido de influência norte-americana em sua formação cruzada com elementos tupiniquins (ALCADIPANI; BERTERO, 2014), seu desenvolvimento se dá em vias paralelas e as críticas que as universidades estrangeiras têm recebido são consoantes às falas dos professores. Um elemento que exemplifica essa equivalência é escassez de prática de mercado no currículo dos professores ou em sua práxis docente (BENNIS; O'TOOLE, 2005; KHURANA, 2010; MILES, 2017), o que provoca déficits de formação percebidos pelos participantes em suas épocas de estudantes e pouco propósito atribuído ao conteúdo ensinado em sala de aula. 
O exercício docente em cursos de Administração recebe críticas negativas derivadas de ambos os extremos nas categorias investigadas. Quando acadêmico ou prático, ao professor que permanece nas extremidades é sugerida uma adequação, um complemento de formação ou experiência que o aproxime da ambidestria dita ideal (MARKIDES, 2007, 2011). Os óbices de comunicação e aproximação entre empresas e universidades são sentidos tanto por aqueles profissionais que tiveram sua formação prévia à docência exclusiva em IES, quanto por aqueles que já se afastaram do meio empresarial e não se sentem inseridos ou confortáveis no contato. Desta forma, a produção de conhecimento pode ser prejudicada e se distanciar das necessidades reais das organizações (GONZALEZ-BRAMBILA et al., 2015). A despeito de estarem inseridos em organizações públicas ou privadas de ensino superior, os professores não mencionam esta participação e parecem desconsiderá-la ao tratar de seus vínculos empregatícios.

A "busca por professores ambidestros" (MARKIDES, 2007) parece ser passível de um resultado positivo. Em consonância aos resultados, alguns elementos são requisitos fundamentais: (i) o debate e reconhecimento de problemas de formação ou falta de experiência prática, que podem ser supridos pelas vias correspondentes, tais como uma pós-graduação stricto sensu para treinamento em pesquisa e parcerias IES-Empresas para aproximação com o mercado; (ii) o uso de recursos didáticos, tais como metodologias ativas e casos de ensino; (iii) a aproximação com a sociedade; (iv) uma reflexão aprofundada sobre o conceito e a aplicabilidade da dedicação exclusiva em cursos da área de gestão, pois esta pode distanciar o professor de seu campo de prática. Assim como argumentam Pfeffer e Fong (2002), não há motivos para que as escolas de negócio falhem e um caminho possível é a adição de variáveis de verificação de quão bem está a atuação prática dos profissionais que formam aos rankings de desempenho institucional.

Wilson e Thomas (2012) asseveram que as mudanças são inevitáveis se as business schools pretenderem manter-se competitivas, independentes às tendências isomórficas e às limitações de escolhas estratégicas. Dentre as mudanças que podem ser propostas, como sugestão, os autores apresentam uma associação com outras ciências em vias de responder a perguntas sociais de ampla preocupação e próxima das realidades da população de modo geral, tais como mudanças climáticas, desastres, terrorismo, pobreza, fome e obesidade. Em caso contrário, a inércia 
pode provocar o descrédito nas instituições e uma atribuição de culpa consequente da falta de competência julgada (PODOLNY, 2009). Contudo, como Miles (2017) explica, universidades são resistentes às mudanças de currículo, mas a história exemplifica que a mudança é célere se elas não podem ignorar vozes externas que questionam sua credibilidade.

De acordo com Ungureanu e Bertolotti (2018), uma possível solução a este dilema seria uma combinação de expertises, a partir de interações que se baseiem em tentativa e erro, com apoio advindo das características marcantes de ambas as categorias, acadêmicos e práticos. Um intercâmbio de conhecimentos seria de grande valia para ambas as classes categóricas, implicando em crescimento simultâneo e, possivelmente, no preenchimento das carências percebidas.

\section{Conclusões}

Esta pesquisa contribui ao oferecer evidências empíricas que auxiliam na compreensão do trabalho docente em cursos superiores de Administração a partir da discussão do papel do profissional formador e da sua formação, ambos analisados em contexto nacional brasileiro. Partindo do questionamento de como docentes, que também são egressos de cursos de Administração, compreendem a possibilidade de uma ambidestria ideal associada à prática de mercado e à pesquisa acadêmica? As contribuições expandem a discussão sobre o ensino e pesquisa brasileiros em administração a partir de enfoque particular, respondendo ao objetivo de analisar as possibilidades de uma ambidestria ideal que envolva a prática de mercado e a pesquisa acadêmica para professores de Administração, percebida como possível, se atendidas as exigências e recomendações. O quadro teórico que traz a discussão sobre a dicotomia entre acadêmicos e práticos na profissão do professor de administração é recente e, por isso, possui poucas referências (CARTON; UNGUREANU, 2017; MARKIDES, 2007; UNGUREANU; BERTOLOTTI, 2018). Os resultados deste estudo trazem, ainda por contribuições, a investigação destas categorias empiricamente conhecidas, mas pouco averiguadas em esforços científicos.

As implicações desta pesquisa para o campo da educação, em síntese, sinalizam que há uma dificuldade percebida nas escolas de formação de profissionais 
no campo acadêmico da administração, como em exemplos que levaram ao debate acadêmico que situou o referencial teórico apresentado, de contextos norte-americanos e o caso brasileiro aqui retratado. A situação é justificada por uma formação parcialmente desconexa com a realidade das organizações, advinda da pouca experiência prática dos professores, por um lado, ou com os resultados de pesquisas que possuem pouca relevância e/ou aplicabilidade, por outro. O ressalte de que estas informações refletem as dificuldades encontradas, mas não uma generalização dos achados para o contexto brasileiro é imprescindível.

Como recomendações, destacam-se uma possível política educacional que vise reduzir os óbices que impedem ou dificultam o equilíbrio da prática docente que associe relevância acadêmica à experiência de mercado. Tanto em resposta à crítica que tem sido constante à lógica que torna perecíveis aqueles que se inserem na rotina de produção acadêmica em série, como à outra via da crítica à práxis que se distancia do mercado. Neste sentido, as limitações do estudo, que implicam novos campos para pesquisa, são derivadas da escolha do objeto, centralizando-se nos educadores. Os discentes, as instituições de ensino e o sistema educacional como um todo, incluindo as agências reguladoras e o Estado podem ser elementos investigados em novas pesquisas que complementem, corroborem ou contrastem os resultados evidentes neste documento.

\section{Referências}

ALCADIPANI, R.; BERTERO, C. O. Uma escola norte-americana no ultramar? Uma historiografia da EAESP. RAE-Revista de Administração de Empresas, v. 54, n. 2, p. 154-169, 2014. DOI: http://dx.doi. org/10.1590/S0034-759020140204.

ALPERSTEDT, G. D.; ANDION, C. Por uma pesquisa que faça sentido. Revista de Administração de Empresas, v. 57, n. 6, p. 626-631, 2017. DOI: 10.1590/s0034-759020170609.

BARDIN, L. Análise de conteúdo. 1. ed. São Paulo: Edições 70, 2011.

BARROS, A. N.; CRUZ, R. C.; XAVIER, W. S.; CARRIERI, A. P.; LIMA, G. C. O. Apropriação dos saberes administrativos: um olhar alternativo sobre o desenvolvimento da área. RAM. Revista de Administração Mackenzie, v. 12, n. 5, p. 43-67, 2011. DOI: 10.1590/S1678-69712011000500003.

BENNIS, W. G.; O'TOOLE, J. How business schools lost their way. Harvard business review, v. 83, n. 5, p. 96-104, 2005.

BERTERO, C. O. Ensino e pesquisa em adminstração. Thomson Learning. 2006. 
BROWN, K. G.; RUBIN, R. S. Management Education in Business Schools. In: WILKINSON, A.; ARMSTRONG, S. J.; LOUNSBURY, M. The Oxford Handbook of Management. Londres: Oxford, 2017. p. 437-443.

CAMARGO, B. V.; JUSTO, A. M. IRAMUTEQ: um software gratuito para análisede dados textuais. Temas em psicologia, v. 21, n. 2, p. 513-518, 2013. DOI: 10.9788/TP2013.2-16.

CARTON, G.; UNGUREANU, P. Bridging the Research-Practice Divide: A Study of Scholar-Practitioners' Multiple Role Management Strategies and Knowledge Spillovers Across Roles. Journal of Management Inquiry, v. 27, n. 4, p. 1-19, 2017. DOI: 10.1177/1056492617696890.

CHIA, R.; HOLT, R. The nature of knowledge in business schools. Academy of Management Learning \& Education, v. 7, n. 4, p. 471-486, 2008.

CHO, C. H.; JUNG, J. H.; KWAK, B.; LEE, J.; YOO, C. Y. Professors on the Board: Do they contribute to society outside the classroom? Journal of business ethics, v. 141, n. 2, p. 393-409, 2017. DOI: 10.1007/ s10551-015-2718-X

CIRANI, C. B. S.; SILVA, H. H. M.; CAMPANARIO, M. A. A evolução do ensino da pós-graduação estrito senso em administração no Brasil. RAC- Revista de Administração Contemporânea, v. 16, n. 6, p. 765783, 2012.

COSTA, T. D.; SALVADOR, P. T. C. O.; RODRIGUES, C. C. F. M.; ALVES, K. Y. A.; TOURINHO, F. S. V.; SANTOS, V. E. P. Percepção de profissionais de enfermagem acerca de segurança do paciente em unidades de terapia intensiva. Revista Gaúcha de Enfermagem, v. 37, v. 3, e61145, 2016. DOI: 10.1590/1983-1447.2016.03.61145.

CURADO, I. B. (2001). O desenvolvimento dos saberes administrativos em São Paulo. 2001. 205 f. Tese (Doutorado em Administração) - Fundação Getulio Vargas, São Paulo, 2001.

CURRIE, G.; DAVIES, J.; FERLIE, E. A Call for University-Based Business Schools to "Lower Their Walls:" Collaborating With Other Academic Departments in Pursuit of Social Value. Academy of Management Learning \& Education, v. 15, n. 4, p. 742-755, 2016. DOI: 10.5465/amle.2015.0279.

GONZALEZ-BRAMBILA, C.; JENKINS, M.; LLORET, A. Challenges for scholarly business research in Latin America. Journal of Business Research, v. 69, n. 2, p. 383-387, 2016.

HIGSON, A.; KASSEM, R. Accounting research: relevance lost. Financial Reporting, v. 1, n. 1, p. 59-76, 2016. DOI: 10.3280/FR2016-001004.

KHURANA, R. From higher aims to hired hands: the social transformation of American business schools and the unfulfilled promise of management as a profession. Princeton, NJ: Princeton University Press, 2010. LAZZARINI, S. Pesquisa em Administração: Em busca de impacto social e outros impactos. Revista de Administração de Empresas, v. 57, n. 6, p. 620-625, 2017. DOI: 10.1590/s0034-759020170608.

$\mathrm{LI}, \mathrm{X}$. Is "Yin-Yang balancing" superior to ambidexterity as an approach to paradox management? Asia Pacific Journal of Management, p. 1-16, 2018. DOI: 10.1007/s10490-018-9569-9

MARKIDES, C. In search of ambidextrous professors. Academy of Management Journal, v. 50, n. 4, p. 762-768, 2007. DOI: 10.2307/20159887.

MARKIDES, C. Crossing the chasm: How to convert relevant research into managerially useful research. The Journal of Applied Behavioral Science, v. 47, n. 1, p. 121-134, 2011. DOI: 10.1177/0021886310388162. MESQUITA, R. F.; MATOS, F. R. N. A abordagem qualitativa nas ciências administrativas: aspectos históricos, tipologias e perspectivas futuras. Revista Brasileira de Administração Científica, v. 5, n. 1, p. 7-22, 2014. DOI: 10.6008/SPC2179-684X.2014.001.0001. 
MESQUITA, R. F.; MEDEIROS, A. K. L.; SENA, A. M. C.; SILVA, M. C.; GOMES, V. M. P. O triênio 20102012 e a nova avaliação de periódicos da Capes. Educação, Ciência e Cultura, v. 18, n. 2, p. 33-47, 2014. MILES, E. W. Professional Schools Displace Practice-Based Training. In: MILES, E. W. The Past, Present, and Future of the Business School. Palgrave Macmillan: Cham, 2016. p. 115-127, 2016.

MILES, E. W. Historical context and insights for criticisms of the 21 st century business school. Journal of Education for Business, v. 92, n. 5, p. 245-254, 2017. DOI: 10.1080/08832323.2017.1335277.

MINAYO, M. C. S. Amostragem e saturação em pesquisa qualitativa: consensos e controvérsias. Revista Pesquisa Qualitativa, v. 5, n. 7, p. 1-12, 2017.

MINTZBERG, H. Managers, not MBAs: A hard look at the soft practice of managing and management development. San Francisco, CA: Berrett-Koehler Publishers, 2004.

MURILLO, D.; VALLENTIN, S. The business school's right to operate: Responsibilization and resistance. Journal of business ethics, v. 136, n. 4, p. 743-757, 2016.

PFEFFER, J.; FONG, C. T. The end of business schools? Less success than meets the eye. Academy of management learning \& education, v. 1, n. 1, p. 78-95, 2002.

PODOLNY, Joel M. The buck stops (and starts) at business school. Harvard business review, v. 87, n. 6, p. 62-67, 2009.

SALTER, A.; SALANDRA, R.; WALKER, J. Exploring preferences for impact versus publications among UK business and management academics. Research Policy, v. 46, n. 10, p. 1769-1782, 2017.

SOUZA-SILVA, J. C. D.; DAVEL, E. Concepções, práticas e desafios na formação do professor: examinando o caso do ensino superior de administração no Brasil. Organizações \& sociedade, v. 12, n. 35, p. 113-134, 2005. DOI: 10.1590/S1984-92302005000400007.

TENKASI, R. V.; HAY, G. W. Following the second legacy of Aristotle: The scholar-practitioner as an epistemic technician. In: SHANI, A. B.; MOHRMAN, S. A.; PASMORE, W. A.; STYMNE, B.; ADLER, N. (Eds.). Handbook of collaborative management research. London, UK: SAGE, 2008, p. 49-72.

TUSHMAN, M.; O'REILLY, C. Research and relevance: Implications of Pasteur's quadrant for doctoral programs and faculty development. Academy of Management Journal, v. 50, n. 4, p. 769-774, 2007. DOI: 10.5465/amj.2007.26279169.

TUSHMAN, M. L.; O’REILLY, C.; FENOLLOSA, A.; KLEINBAUM, A. M.; MCGRATH, D. Relevance and rigor: Executive education as a lever in shaping practice and research. Academy of Management Learning \& Education, v. 6, n. 3, p. 345-362, 2007.

VERMEULEN, F. On rigor and relevance: Fostering dialectic progress in management research. Academy of Management Journal, v. 48, n. 6, p. 978-982, 2005. DOI: 10.2307/20159722.

VIZEU, F.; MACADAR, M. A.; GRAEML, A. R. Produtivismo acadêmico baseado em uma perspectiva habermasiana. Cadernos EBAPE. BR, v. 14, n. 4, p. 984-1000, 2016. DOI: 10.1590/1679-395137603.

VOSGERAU, D. S. A. R.; ALMEIDA, E. O.; MEYER, P. Produtivismo acadêmico e suas repercussões no desenvolvimento profissional dos professores universitários. Educação \& Sociedade, v. 38, n. 138, p. 231-247, 2017. DOI: 10.1590/es0101-73302016163514.

WILSON, D. C.; THOMAS, H. The legitimacy of the business of business schools: what's the future? Journal of Management Development, v. 31, n. 4, p. 368-376, 2012.

UNGUREANU, P.; BERTOLOTTI, F. Building and Breaching Boundaries at Once. An Exploration of How Management Academics and Practitioners Perform Boundary Work in Executive Classrooms. Academy of Management Learning \& Education, amle-2016. 2018. DOI: 10.5465/amle.2016.0095. 